\title{
Schwannoma of the medial plantar nerve: a case report
}

\author{
Adriano Machado Filho ${ }^{\mathbb{D}}$, Jefferson Soares Martins ${ }^{2} \mathbb{D}$, Paulo Victor de Souza Pereira ${ }^{3} \mathbb{D}$, Ademir Freire de Moura Júnior ${ }^{2} \mathbb{D}$ \\ 1. Hospital das Clínicas - EBSERH/UFG, Goiânia, GO, Brazil. \\ 2. Hospital de Urgências de Goiânia (HUGO), Goiânia, GO, Brazil \\ 3. Hospital Estadual de Urgências de Aparecida de Goiânia Cairo Louzada (HUAPA), Aparecida de Goiânia, GO, Brazil.
}

\begin{abstract}
We report the case of a 60-year-old woman with a schwannoma of the medial plantar nerve. She presented with the complaint of pain for about 2 years and a painful lesion in the medial plantar region of the left forefoot and on the second toe. Physical examination showed well-defined, firm tumor masses painful to palpation on the medial and plantar surface of the left forefoot and second toe. We surgically explored the area and excised 3 lesions, resulting in complete pain relief and no aesthetic complaints. Schwannomas of the medial plantar nerve are rare tumors, with only a few reports of cases extending to the forefoot. The finding of multiple schwannomas may be a red flag for the possible existence of local, painful, nerve lesions despite a negative Tinel sign. Appropriate surgical planning contributed to our successful intervention, without aesthetic, painful, or functional sequelae for the patient.
\end{abstract}

Level of Evidence V; Therapeutic Studies; Expert Opinion.

Keywords: Neurilemmoma; Foot; Neoplasms.

\section{Introduction}

Schwannoma or neurilemmoma are terms currently used to designate a benign myelin sheath tumor that arises from Schwann cells of the peripheral nerves. When located at the extremities, these tumors may be confused with a lipoma or a synovial cyst, being treated surgically when they become painful(1).

Most schwannomas are sensitive nodules associated with neurogenic pain or paresthesia. Surgical removal is indicated for the relief of symptoms and adequate diagnosis of the tumor, which is rarely malignant ( $1 \%$ of cases) (2). Tumor removal does not compromise nerve integrity and may result in symptom relief and maintenance of nerve function. Schwannomas account for $5 \%$ of all benign soft tissue neoplasms, with a low local recurrence rate. They are usually isolated, solitary, slow-growing, well-encapsulated lesions ${ }^{(3)}$.

These tumors are uncommon in the foot. In a review of 32 years' experience, only 12 of 104 cases were located in the foot $^{(4)}$. Schwannoma of the medial plantar nerve is a rare tumor, with only a few cases in the literature and even fewer cases of schwannomas extending medially to the plantar surface of the foot. Case reports are mostly of adults between 30 and 49 years of age, with no predilection for race or sex ${ }^{(5)}$.

We report the case of an older woman with 3 neurilemmomas of the medial plantar nerve that were surgically resected.

\section{Case Description}

This rare case was reported after obtaining approval from the local ethics committee and written consent from the patient.

An otherwise healthy 60-year-old woman presented with the complaint of pain for about 2 years and a painful lump on the second toe of her left foot. Physical examination showed tumors on the medial and plantar surface of the left forefoot and on the medial surface of the second toe of the same foot (Figure 1). The patient had no history of trauma and no family history of neurofibromatosis. Foot examination revealed a negative Tinel sign, but with decreased sensitivity (hypoesthesia) and pain while walking.
Study performed at the Hospital das Clínicas de Goiânia, Goiânia, GO, Brazil.

Correspondence: Adriano Machado Filho. Rua T-37, 3000, Setor Bueno, Ônix Bueno, Apt. 1411 - 74230-025, Goiânia, GO, Brazil. E-mail: adrianomf_5@hotmail.com Conflicts of interest: none. Source of funding: none. Date received: June 27, 2021. Date accepted: July 03, 2021.Online: August 31, 2021.
How to cite this article: Machado Filho A, Martins JS, Pereira PVS, Moura Júnior AF. Schwannoma of the medial plantar nerve: a case report. J Foot Ankle. 2021;15(2):171-4. 
Plain radiographs of the foot and ankle showed no bone or joint abnormalities, only soft tissue enlargement. Magnetic resonance imaging revealed an oval mass adjacent to the medial plantar nerve and 2 similar but smaller lesions on the second toe of the left foot (Figure 2). Under spinal anesthesia, we surgically explored the area (Figure 3 ) and excised 3 lesions (Figure 4).
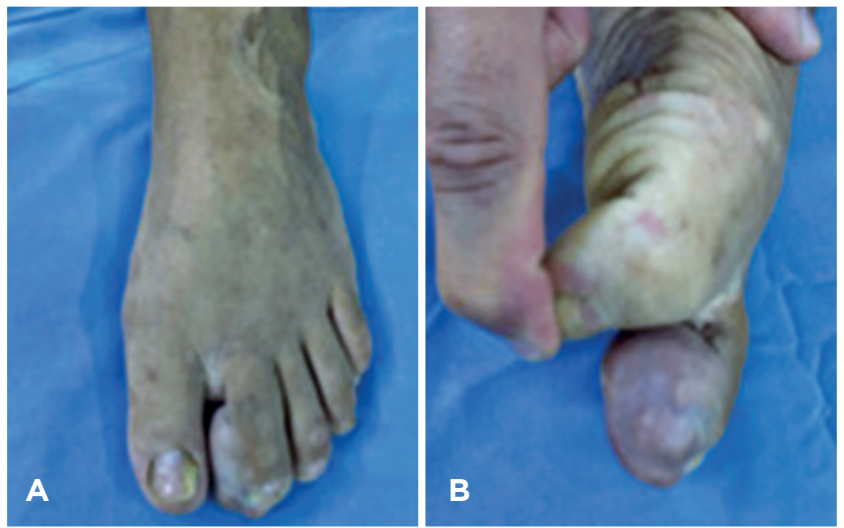

Figure 1. Non-weight-bearing photograph of the left foot in A) front view and $B$ ) medial view showing a firm mass on the second toe.

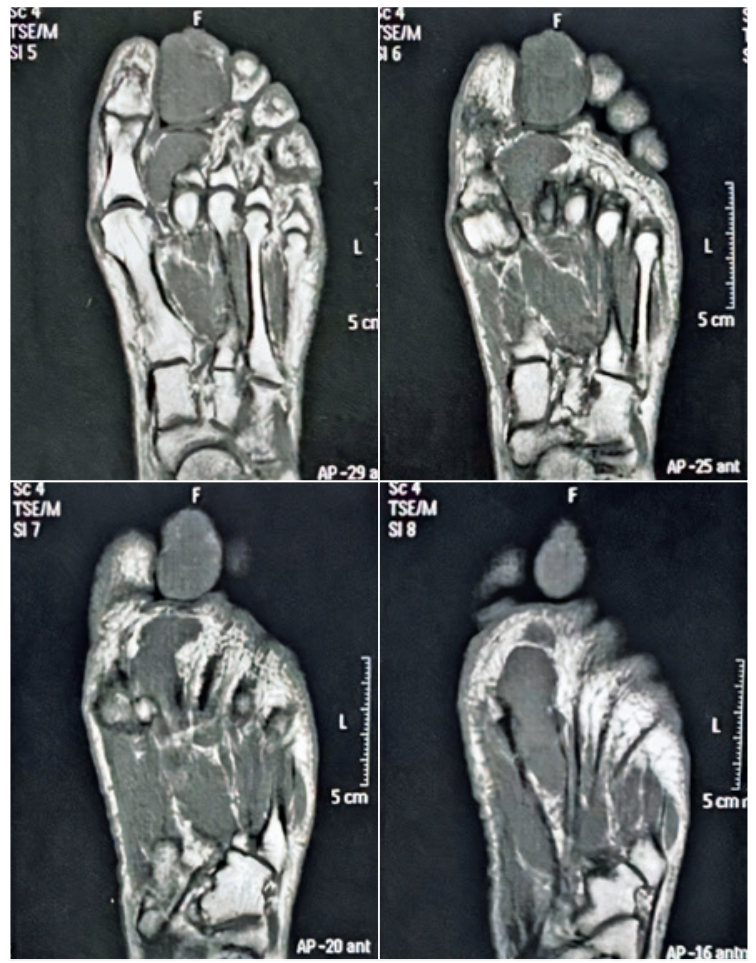

Figure 2. Magnetic resonance imaging of the left foot showing a cystic lesion hypointense on T1-weighted sequences on the medial and plantar surface of the second toe along the course of the medial plantar nerve.
Gross pathological examination of the 3 lesions showed irregularly shaped tissue specimens with a yellowish-brown color and fibroelastic consistency, measuring $7.4 \times 2.8 \times 1.8 \mathrm{~cm}$ and weighing $30 \mathrm{~g}$. Microscopic evaluation revealed a fusiform mass characterized by alternating hypercellular and hypocellular areas. Given the absence of necrosis, mitosis, and nuclear atypia, the diagnosis of schwannoma was made.

\section{Surgical technique}

With the patient in the supine position under spinal anesthesia with a pneumatic tourniquet applied proximally on the left thigh, we made a wide incision of approximately $10 \mathrm{~cm}$ on the medial surface of the forefoot using a No. 15 scalpel blade, opened it in layers, identified a well-defined fibroelastic tumor of nervous origin, and resected it with free margins. We then made an incision of approximately $4 \mathrm{~cm}$ on the medial surface of the second toe, identified a well-defined fibroelastic tumor, and resected it with free margins. We removed the tourniquet and, once hemostasis was achieved, we closed the wound in layers and covered it with a sterile
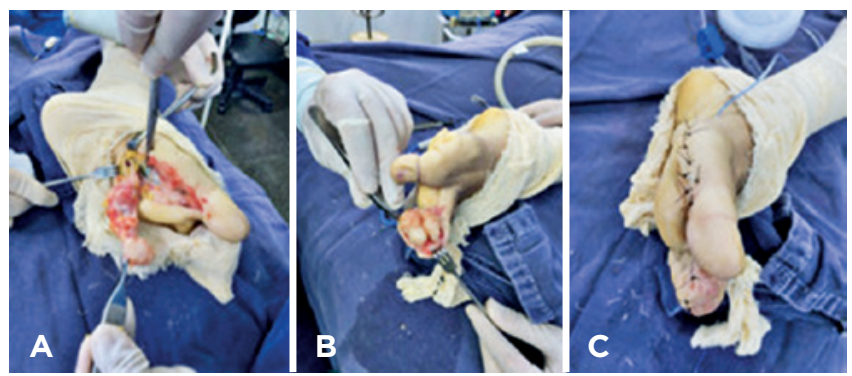

Figure 3. Intraoperative photograph of the left foot in medial view showing the removal of schwannomas from $A$ ) the first metatarsal and B) the second toe. C) Postoperative photograph after removal of schwannomas.

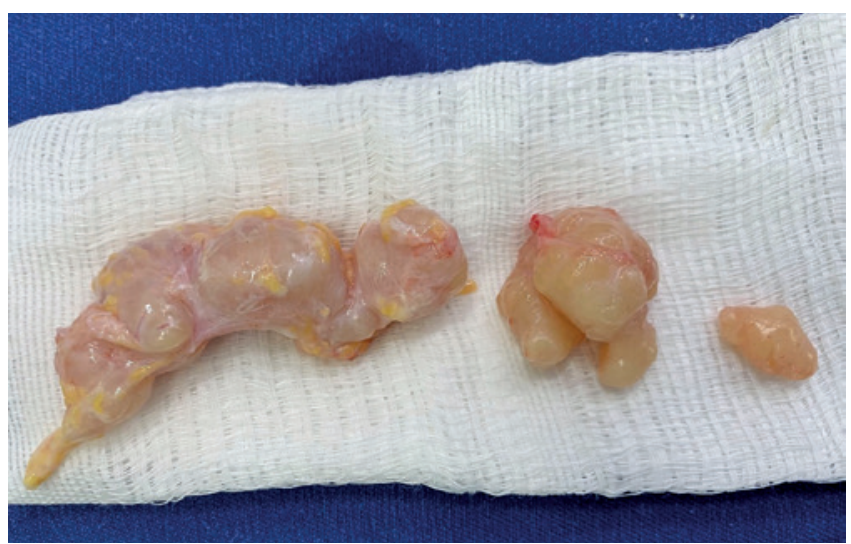

Figure 4. Resected tumors showing a yellowish-brown color and fibroelastic consistency. 
dressing. The patient was discharged home 24 hours after the procedure. Postoperatively, there were no neural, sensory, or motor deficits. At 15 days after surgery, the patient was able to walk without pain and had no aesthetic complaints, and the stitches were removed (Figure 5). At 45-day review (Figure 6), the wound had healed completely, and the patient had no complaints. During the 1-year follow-up, she reported numbness in the plantar region of the foot, which was treated with pregabalin $75 \mathrm{mg}$ at night and use of hard-soled sandals for 90 days. After 90 days, she was allowed to wear normal shoes without walking aids, with no later complaints.

\section{Discussion}

Schwannomas or neurilemmomas are rare and almost always solitary tumors, although there are reports of multiple tumors in a single nerve, as described by Patel et al. ${ }^{(6)}$. They surgically removed 5 schwannomas of the ulnar nerve in a 37-year-old male patient complaining of painful masses in the right distal forearm, palm, and ring finger.
Schwannomas preferentially affect the flexor surface of the extremities, being more common in adults between 40 and 60 years of age, with no predilection for race or sex. Although schwannomas are rarely found in the foot, Angelini et al.(7) described 4 consecutive cases: a 57-year-old woman with a mass arising from the medial plantar nerve, a 45-year-old man with a schwannoma in the plantar region, a 58-year-old woman with a schwannoma arising from the sural nerve, and a 35-year-old woman with a tumor arising from the medial plantar nerve. All patients underwent surgical excision of the tumors and histological evaluation. Postoperatively, no signs of neurological deficit or tumor recurrence were observed at the final follow-up.

In most cases of schwannoma, the primary complaints include pain and/or numbness, and the precise localization of these symptoms is important to identify the compromised peripheral nerve. Because most schwannomas located in the foot present as slow-growing masses, patients might not seek medical care early, thus delaying clinical diagnosis for years ${ }^{(8)}$.

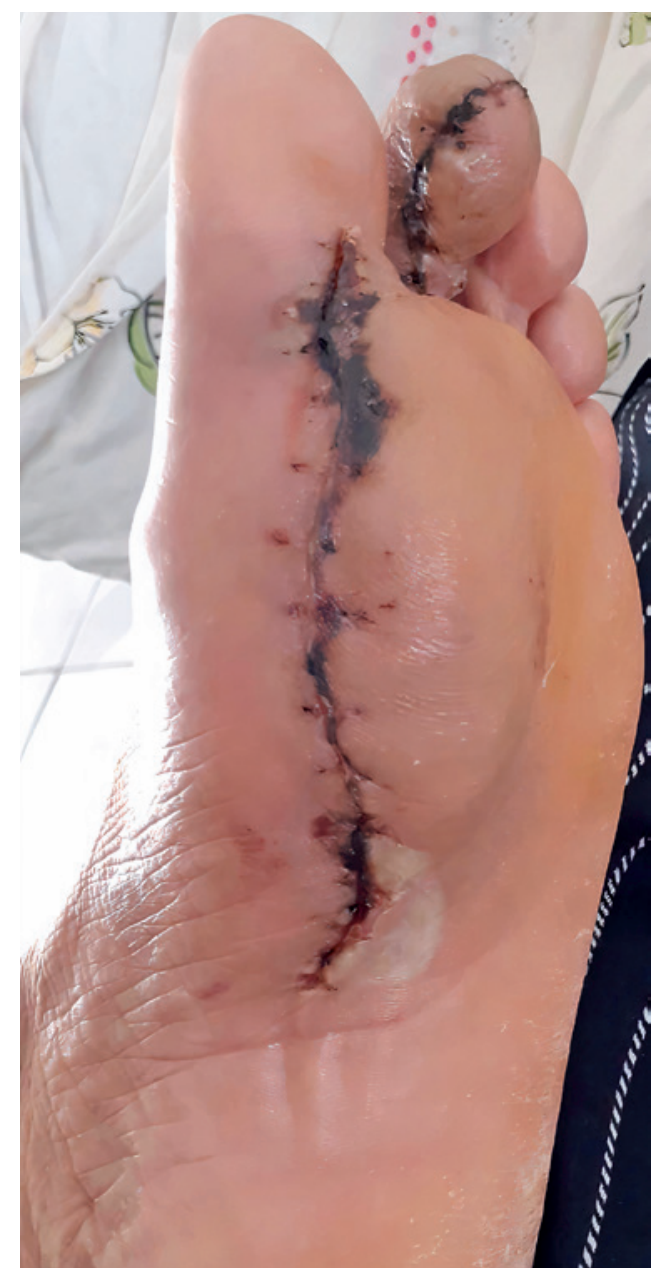

Figure 5. Surgical wound at 15 days postoperatively.

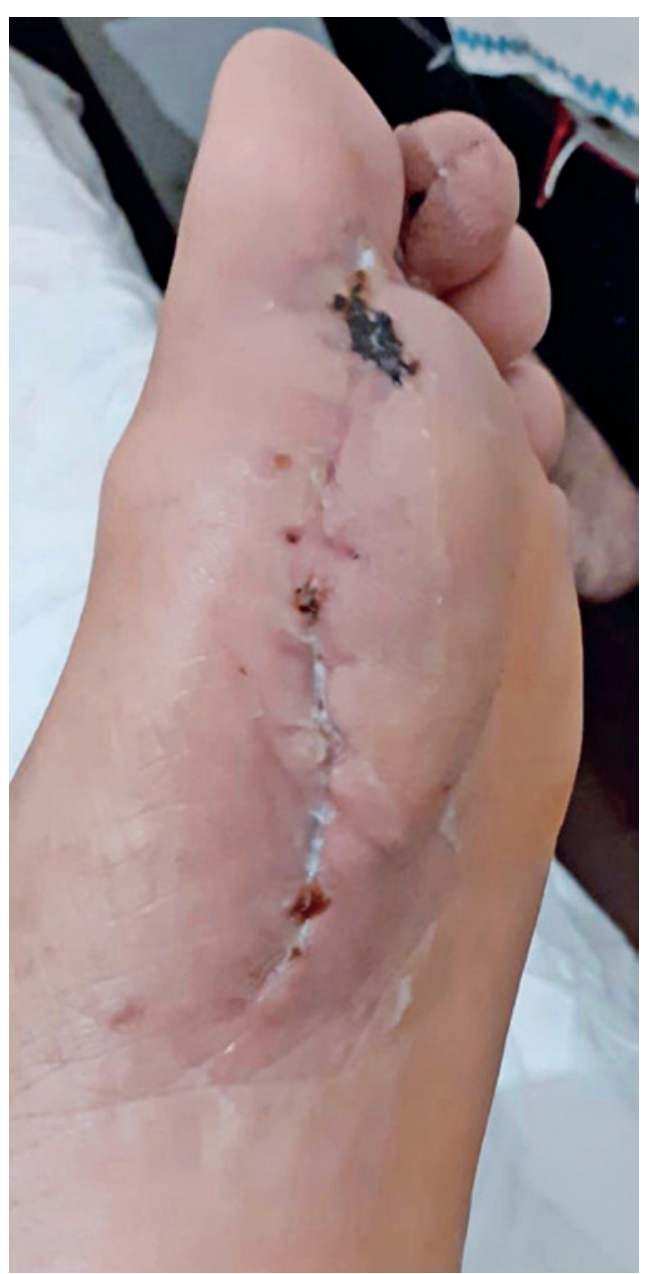

Figure 6. Surgical wound at 45 days postoperatively. 
Surgical excision is not always required, being recommended only in cases of large tumors arising from major peripheral nerves and in the presence of compressive symptoms ${ }^{(2)}$, since a small, localized schwannoma can affect the plantar surface of the foot during activities such as walking and jumping, thus resulting in pain symptoms ${ }^{(9)}$. Postoperative morbidity resulting from surgical excision of schwannomas of the foot is minimal when the excision is properly performed, and local tumor recurrence is $\operatorname{rare}^{(8)}$.

Factors such as the absence of a specific clinical diagnostic test, the variety of signs and symptoms, the rarity of the lesion, and a slow and painless growth for several years are associated with a delay in seeking care and in making the diagnosis ${ }^{(10)}$.

\section{Conclusion}

We reported a rare case of schwannoma of the medial plantar nerve. The finding of multiple schwannomas may be a red flag for the possible existence of local, painful, nerve lesions despite a negative Tinel sign. Magnetic resonance imaging is a useful tool for the assessment and detection of schwannomas. Surgical excision with careful nerve dissection appears to be the most feasible treatment for this peculiar condition that may affect the foot. Appropriate surgical planning contributed to our successful intervention, without aesthetic, painful, or functional sequelae for the patient.

Authors' contributions: Each author contributed individually and significantly to the development of this article: AMF *(https://orcid.org/O000-00019620-7222) Conceived and planned the activities that led to the study, participated in the review process, participated in the writing of the article, data collection, approved the final version; JSM *(https://orcid.org/0000-0003-4742-1905) Interpreted the results of the study, participated in the review process, participated in the writing of the article, approved the final version; PVSP *(https://orcid.org/0000-0002-9538-8479) Participated in the review process, bibliographic review, survey of the medical records, participated in the writing of the article, approved the final version; AFMJ *(https://orcid. org/0000-0002-6430-8974) Participated in the review process, formatting of the article, participated in the writing of the article, approved the final version. All authors read and approved the final manuscript. * ORCID (Open Researcher and Contributor ID) (iD).

\section{References}

1. Renaud M, Paolo M, Ali C. Neurilemoma in the ankle as a cause of plantar foot pain: A report of one case. J Foot Ankle Surg. 2006;12(4):215-18.

2. Carter J, Ben-Ghashir N, Chandrasekar CR. Giant schwannoma of the medial plantar nerve. Foot (Edinb). 2016;26:4-6.

3. Albert P, Patel J, Badawy K, Weissinger W, Brenner M, Bourhill I, et al. Peripheral Nerve Schwannoma: A Review of Varying Clinical Presentations and Imaging Findings. J Foot Ankle Surg. 2017;56(3):632-37

4. Kehoe NJ, Reid RP, Semple JC. Solitary benign peripheral-nerve tumours. Review of 32 years' experience. J Bone Joint Surg Br. 1995;77(3):497-500

5. Merritt G 4th, Ramil M, Oxios A, Rushing C. Schwannoma of the plantarmedial aspect of the foot: A case report. Foot (Edinb). 2019;39:85-7.
6. Patel MR, Mody K, Moradia VJ. Multiple schwannomas of the ulnar nerve: a case report. J Hand Surg Am. 1996;21(5):875-6.

7. Angelini A, Bevoni R, Biz C, Cerchiaro MC, Girolami M, Ruggieri $P$. Schwannoma of the foot: report of four cases and literature review. Acta Biomed. 2019;90(1-S):214-20.

8. Carvajal JA, Cuartas E, Qadir R, Levi AD, Temple HT. Peripheral nerve sheath tumors of the foot and ankle. Foot Ankle Int. 2011;32(2):163-7.

9. Nishio J, Mori S, Nabeshima K, Naito M. Successful enucleation of large multinodular/plexiform schwannoma of the foot and ankle. Springerplus. 2015;4:260

10. Jonathan CK, Fu-Keung IP, Tak-Chuen W, Prisilla LO, Sze-Yan C. Neurilemmomas of the hand: a review of the clinical presentation, surgical outcome, and potential risk factors. J Orthop Trauma Rehabil. 2017;22(01):48-51. 